Do Individual and Program Factors Matter in the Utilization of Maternal Care Services in Rural India? A Theoretical Approach

\author{
T.S. Sunil, Ph.D. \\ University of Texas at San Antonio \\ S. Rajaram, Ph.D. \\ Population Research Center, Dharwad, India \\ Lisa K. Zottarelli, Ph.D. \\ Texas Woman's University
}

For correspondence:

T.S. Sunil, Ph.D.

Assistant Professor

Department of Sociology

The University of Texas at San Antonio

6900 North Loop 1604 West

San Antonio, TX 78249

tsunil@utsa.edu

210-458-5617

210-458-4629 (FAX) 


\title{
Do Individual and Program Factors Matter in the Utilization of Maternal Care Services in Rural India? A Theoretical Approach
}

\begin{abstract}
Current studies on the utilization of maternal care services in India focus on individual factors. In the present study, we use the theoretical model developed by Andersen and Newman (1973) to understand the utilization of maternal care services in rural areas of India. This theoretical model accommodates individual, and program (or system factors) to study health care utilization. Data collected through the National Family Health Survey-2 are used in the present study. The study results suggest that in addition to individual characteristics, program and system factors influence the utilization of maternal care in rural areas. Program factors, particularly educational activities promoting the benefits of maternal care services carried out through Mahila Mandal and Anganwadi Centers, are important in increasing the use of maternal care services in rural areas. Additionally, the results indicate that the mere presence of a private health care facility need not necessarily improve utilization. Increase in utilization is observed among households if the health worker visited these households during pregnancy. More statespecific studies incorporating both program and individual characteristics are recommended to further strengthen our understanding of the utilization of health care services in general and maternal care services specifically.
\end{abstract}

Key words: maternal care services, utilization, program factors, individual factors, multilevel analysis. 


\section{Do Individual and Program Factors Matter in the Utilization of Maternal Care Services in Rural India? A Theoretical Approach}

Introduction

In the years following the International Conference on Population and Development (ICPD) in 1994 and the Fourth World Conference on Women in 1995, there have been dramatic changes in population policies and programs around the world. Particularly in developing countries, the consequence of this paradigm shift has changed the focus of these policies and programs from population control to reproductive health emphasizing a holistic approach to women's health and well-being (Lane, 1994). The ICPD advocated population programs aimed to facilitate couples to have children as they desire in timing and number and also to assist mothers through pregnancy and childbirth safely so that the outcome of pregnancy is successful in terms of maternal and infant survival and well-being. Following the recommendations of ICPD, the Indian Family Welfare Program (IFWP) went through many policy changes towards population control.

One area where such change took place was the emphasis on utilization of maternal care services. Prior to this conference, IFWP was designed to provide minimum maternal care services to ensure safe delivery and better child survival. The program was targeted to meet demographic goals through increasing contraceptive prevalence primarily via female sterilization. Unfortunately, similar to other developing countries, during this era the IFWP was not designed to address causes of mortality due to labor, delivery and complications during the postpartum period (Abou-Zahr and Wardlaw, 2003). The current national Health and Family Welfare Program, renamed Reproductive and Child Health $(\mathrm{RCH})$ Program, combined all the related programs of Child Survival and Safe Motherhood (CSSM) initiated during 1992-93. Under this new approach, the RCH 
program intends to take into account the community's needs and thus aims to improve quality of services instead of a mere fulfillment of targets. In this respect, there are no pre-specified targets for various services. Instead, the grass-root level workers are expected to assess the needs of the community in consultation with that community. Based on their assessment, goals are formulated for various health and family welfare activities in the community. Thus the concept of $\mathrm{RCH}$ is to provide needs-based, clientcentered and demand-driven integrated services to the beneficiaries.

The important elements of the program for maternal care include the provision of antenatal care, the encouragement of institutional deliveries or deliveries at home assisted by a trained health professional and the provision of postnatal care. The important role of these elements in improving reproductive health of women is undisputed (WHO, 1989; Magadi, Madise and Rodrigues, 2000). Furthermore, several studies have shown the importance of providing health care services to mothers during and after pregnancy (Ben Yousssef and Wessen, 1974; Abbas and Walker, 1986; Kwast et al., 1986; Obermeyer and Potter, 1991; Bhatia, 1993). For example, the lack of antenatal care services is associated with maternal mortality (Bhatia, 1993), particularly mortality related to eclampsia, poor birth outcomes (Abou-Zahr and Wardlaw, 2003), and higher risk of perinatal and neonatal mortality (Ramachandran, 1989).

According to National Family Health Survey -2 (NFHS -2) in India, conducted during 1998-1999, only 20 percent of mothers received all the recommended types of antenatal care, 34 percent of births were delivered in a medical institution, 42 percent of deliveries were assisted by a health professional and 17 percent of non-institutional deliveries had a postpartum check-up within two months of birth (IIPS and ORC Macro, 
2000). Wide differentials are also observed between rural and urban areas. The recommended minimum of three antenatal care follow-up visits were received by 69 percent of births to mothers living in urban areas, but for only 37 percent of births to mothers living in rural areas (IIPS and ORC Macro, 2000). Similarly, two-thirds of deliveries in urban areas, while only one-quarter of deliveries in rural areas, took place in health care facilities. These measures indicate that the utilization of various maternal care services are not encouraging, particularly in the rural areas.

Although several studies have addressed the importance and determinants of the use of maternal care in India, many limitations are noted in these studies. First, while prior studies on utilization of maternal care in India have focused on individual characteristics (Bhatia and Cleland, 1995; Raghupathy, 1996; Navaneetham and Dharmalingam, 2002), the effects of program components seldom received any attention. Many studies have approached the use of health care services as a behavioral phenomenon (Becker et al., 1993; Chakraborty et al., 2003), while the quality and cost of and access to services are not included. Recently, analysis using the National Family Health Survey -1 (NFHS -1) indicated that community access to health facilities is not an important factor in explaining the utilization of various antenatal care services (Das et al. 2001). Studies from western societies, however, have often argued that the use of health care services is not determined merely by design and delivery strategies but also by the characteristics of potential users (Andersen and Newmen, 1973; Phillips et al., 1998). In other words, the mere existence of health care facilities may not ensure utilization. While these studies argue the importance of both individual and program factors they are often considered independently. This indicates a lack of conceptualization and use of 
theoretical approaches in studying maternal care utilization, particularly studies from India. Thus, studies on maternal care utilization combining individual and program factors will fill this gap in the literature and thus further strengthen our understanding the varying differentials in maternal care utilization.

While previous studies from India focused either at regional (Kanitkar, and Sinha, 1989) or state levels (Bhatia and Cleland, 1995), sub-national variations in the use of maternal care are few and far between. For example, sub-national variations in the use of maternal care are found between rural and urban areas. As mentioned earlier, six out of ten mothers in rural areas in India did not receive the minimum recommended antenatal visits as compared to three out of ten mothers in urban areas. Similarly, approximately three quarters of the births to mothers living in rural areas took place outside of a health care facility, contrasted against one-third of births in urban areas. Thus, there is a need to focus on rural areas to better understand the factors influencing this disparity in the use of maternal care in these areas.

Another limitation found in the literature is the lack of separation between public and private health care facilities in the analysis. Although a thriving private medical sector exists in India, studies have not considered a potential distinction between the medical care provided in private and public sector settings (see for example, Raghupathy, 1996; Navaneetham and Dharmalingam, 2002). Public health care in rural areas is concentrated on prevention and promotion services to the disadvantage of curative services. The rural primary health centers are woefully underutilized because they fail to provide their clients with the desired amount of attention and medication and because they have inconvenient locations and long waiting times. Furthermore, the differences of 
roles for public and private health care facilities can be illustrated in their provision of services. Public hospitals provide 60 percent of all hospitalizations, while the private sector provides 75 percent of all routine care (Duggal, 1994). Since there exists significant differences in individual characteristics of people who access these facilities in terms of availability and quality of services, it is recommended to consider access to government and private health facilities separately. This is because affordability and quality play a critical role in the decision to use health care services in situations where services are available and accessible.

A final limitation in the literature on maternal care in India that is addressed in this study is the differences found in defining maternal care service provision via health care facilities. Studies have considered one or more of five maternal care services such as, the number of antenatal visits, whether the mother received iron and folic acid tablets/syrup for more than three months, if two tetanus toxoid shots were administered, the place of delivery and assistance during delivery by a trained health personal (Bhatia and Cleland, 1995; Navaneetham and Dharmalingam, 2002). The majority of previous studies on the utilization of maternal care services often considered these components independently. Analysis conducted in this manner may not reflect the true pattern of utilization of services because some women may utilize a few but not all of the five components of the maternal care services. For example, one woman may go for antenatal care services but not deliver in a health facility. By analyzing these aspects separately, one fails to capture the prevailing level of utilization of maternal care services.

In the present analysis we address the above-mentioned limitations using a theoretical framework developed by Andersen and Newman (1973). This approach 
incorporates both individual and program characteristics in addressing the utilization of maternal care services in rural areas of India. To capture the complexity of the various aspects of maternal care utilization we construct a composite index based on the various components of the maternal care services. The analysis based on such an index may provide a better picture of the utilization of maternal care services.

\section{Conceptual framework}

It is generally accepted that use of health care services in any given society is a complex behavioral phenomenon (Andersen and Newman, 1973; Becker et al., 1993; Chakraborty et al., 2003). Although behavioral scientists have explained individual behavior as a function of individual and societal forces as well as the interaction between individual and societal forces (Moore, 1969), many studies have used only individual characteristics such as mother's education, place of residence, birth order, and status of living among many other social, economic and demographic variables to study health care utilization (Elo, 1992; Bhatia and Cleland, 1995; Celik and Hotchkiss, 2000; Matsumura and Gubhaju, 2001; Navaneetham and Dharmalingam, 2002). One of the most widely used analytical models to describe the use of health care services was developed by Andersen (1968). He assumed that the use of medical care by an individual was a function of demographic, social and economic characteristics of the family as the unit of analysis. Later developments in this direction recommended the unit of analysis to be the individual. Expanding this approach further, Andersen and Newman (1973) identified three sets of determinants, which influence health service utilization namely, societal determinants, system determinants (program factors) and individual determinants. This model incorporated "individual, environmental, and provider-related 
variables" in studying individuals' seeking medical care (Andersen, 1995; Phillips et al., 1998). Societal and system determinants are postulated to influence individual determinants, which directly influence the use of health care services. Social determinants include the current state of knowledge as well as people's attitude and beliefs about health and illness. System factors include health service resources and the organization of health services. Resources mainly include structures and activities through which health care and health education are provided (Aday and Andersen, 1974). For example, system factors would consider the availability of information, education and communication (IEC) activities in a village to educate women on maternal care services. The organizational component of system factors addresses the coordination between medical personnel and facilities. That is, how services are delivered to people who are in need. These include the distance to the nearest health facility, household visits by health workers and similar characteristics associated with delivery of services. However, it is individual determinants that are directly related to health care service utilization. Individual determinants of health service utilization include demographic factors, societal structure, family factors, community factors, illness level and evaluated health condition by health personnel. It is assumed that societal and system factors operate either directly to influence the individual determinants or indirectly through system factors. Thus, the present model incorporates characteristics of both the health care system and of the population at risk, specifically, mothers who are in need of these services. This model was first developed and has been extensively used to explain utilization of medical care services in the US. Further details of this model can be found in Andersen and Newman (1973) and Aday and Andersen (1974). 


\section{Data}

The present study uses data from the large-scale national sample survey, National Family Health Survey -2 (NFHS-2) conducted in India during 1998-2000. The NFHS dataset is similar to that of the Demographic and Health Surveys conducted in many other countries. The details of the sample design and implementation of the survey can be obtained from the all India NFHS report (IIPS and ORC Macro, 2000). Relevant questions on safe motherhood were included in the Women's Questionnaire. The topics covered include pregnancy complications, antenatal and postnatal care, place of and assistance during delivery, delivery characteristics, and postpartum complications. For the present analysis, the maternal care services of antenatal visits, tetanus toxoid injections, iron and folic acid tablets or syrup, delivery place and assistance during delivery are considered. Results presented in this paper pertain only to last births, which took place within three years preceding the date of interview. In total in the rural areas, there were 22,406 women with last births during the three years preceding the survey. Due to missing observations for some of the factors considered, the number of women included in the final analysis is reduced to 21,016 . In addition, information on relevant program and community level variables are extracted from the village data file.

\section{Methodology}

Instead of considering various maternal care services separately, a composite index based on the utilization of various maternal care services is constructed to explain their utilization in rural India. The different types of maternal care services considered for the construction of this composite index include: number of antenatal visits, whether the mother received enough iron and folic acid tablets/syrup for more than three months, 
whether the mother received two tetanus toxoid injection, whether the birth was delivered in a medical institution and whether the delivery was assisted by a trained health personnel. Responses to these questions are used to develop a composite index on the status of utilization of maternal care services. The utilization index is created using Principal Component Analysis (PCA). The scores are further grouped into five categories namely, "Poor", "Fair", "Average", "Good" and "Excellent." This index is used as the dependent variable in the analysis. The list of individual and program characteristics is provided in Table 1. Since program factors are at a different level from individual factors, in the present study, we often call program factors community level characteristics. These variables reflect the nature of the program exist at the community level in the rural areas in India.

Insert Table 1 about here

Unlike earlier studies, this paper considers access to government and private health facilities separately. In this analysis, four groups of distance to health facilities are considered, such as facilities available within $1 \mathrm{KM}$ (Kilo meter), within 1-4 KMs, 5-9 KMs and 10+ KMs.

First, bivariate relationship between the utilization index and individual and program characteristics is examined. Multilevel ordered logit regression is used to explain the important individual and community level determinants of utilization of maternal care services. A brief description of the ordered logit model is presented below.

Ordered logit models are used to estimate relationship between an ordinal dependent variable and a set of independent variables. In ordered logit, an underlying score is estimated as a linear function of the independent variables and a set of cut-points. 
The probability of observing outcome ' $i$ ' corresponds to the probability that the estimated linear function, plus random error, is within the range of the cut-points estimated for the outcome:

$$
\operatorname{Pr}\left(\text { outcome }_{j k}=i\right)=\operatorname{Pr}\left(\mathrm{K}_{i-1}<\mathrm{bX}_{j k}+\mathrm{dZ}_{k}+\mathrm{m}_{k}+\mathrm{e}_{j k}<=\mathrm{K}_{i}\right)
$$

$\mathrm{X}_{j k}$ : individual control variables, $\mathrm{Z}_{k}$ : observed community variables, $\mathrm{m}_{k}$ : error of unobserved community variables, $\mathrm{e}_{j k}$ : error of unobserved individual variables, $\mathrm{b}$ and $\mathrm{d}$ are the coefficients for individual and community level variables. $\mathrm{m}_{k}+\mathrm{e}_{j k}$ is assumed to be logistically distributed in ordered logit. In either case, one estimates the coefficients b and $\mathrm{d}$ together with the cut-points $\mathrm{K}_{1}, \mathrm{~K}_{2}, \ldots \mathrm{K}_{i-1}$, where " $i$ " is the number of possible outcomes.

\section{Results}

As a component of antenatal care, the Reproductive and Child Health Program recommends women receive two doses of tetanus toxoid via injection, adequate amounts of iron and folic acid tablets or syrup for more than three months and at least three antenatal check-ups. Based on these recommendations, the current data show that 36.9 percent of rural mothers had three or more antenatal check-ups, 42.5 percent received the recommended levels of iron and folic acid tablets/syrup for three or more months and 62.7 percent received two or more tetanus toxoid injections (see Table 2). Regarding delivery care, it was found that 24.6 percent of rural mothers delivered in a medical facility and 33.7 percent of deliveries were assisted by a trained health professional.

Insert Table 2 about here

The results of the composite index created based on the five maternal care services are presented in Table 3. 
Insert Table 3 about here

The index on utilization of maternal care services indicates that 22.9 percent of mothers in rural India have "poor" utilization, while utilization was "excellent” for 21.2 percent of mothers. Utilization of services by women aged 30 and above is found to be very poor, while a greater percentage of women (37.3 percent) in their first order of births are found to be "excellent." The use of maternal care declines sharply with increase in birth order. The proportion of births where mothers utilized excellent maternal care services increases sharply with the increase in education of either parent. For example, in the case of mother's education, only 10 percent of illiterate mothers received "excellent" maternal care services compared to 63 percent of mothers who completed at least high school. There is a substantial variation in the likelihood of utilization of maternal care services by religion. Only 18 percent of the births to Muslim women received "excellent" maternal care services compared to 38 percent of births to women belonging to religions other than Hindu and Islam. The utilization of maternal care services was "poor" among births to the scheduled tribe mothers compared to mothers of other caste/tribe. The likelihood of utilization of maternal care service was "excellent" among births to mothers living in households with a high standard of living (48 percent for high standard of living compared with 13 percent for low standard of living). Mother's exposure to mass media also improves the utilization of maternal care services. For example, mothers who had the exposure to three or four mass media have used "excellent" maternal care services contrasted against mothers with no mass media exposure.

The bivariate relationship between program and community level characteristics and utilization of maternal care services is provided in Table 4. 
Insert Table 4 about here

It is found that the likelihood of utilization of maternal care is excellent among births to mothers who are visited by a health worker during pregnancy. Similarly, the utilization of maternal care services is "excellent" among mothers who are living in a village, having transportation facility within the village, education and communication (IEC) activities of health and family are carried out during the last one year, where a health professional is available within the village, a government health facility is available within the village, where a private health facility is available within the village, having mahila mandal ${ }^{1}$ or having anganwadi center ${ }^{2}$. These indicators show the importance of both program and community level factors in explaining the utilization of maternal care services in rural India.

Table 5 shows the differentials in the utilization of maternal care services by state.

Insert Table 5 about here

This table shows that utilization of maternal care services is "excellent" among mothers in Kerala (92 percent), followed by Goa (87.4 percent) and Tamil Nadu (69.3 percent). However, only less than 10 percent of mothers in Bihar (8.1 percent), Madhya Pradesh (7.5 percent), Meghalaya (6.1 percent), Nagaland (6.4 percent), Rajasthan (9 percent) and Uttar Pradesh (5.7 percent) have utilized all five maternal care services. The percentages for other states show relatively well in the utilization of maternal care services. These states include Andhra Pradesh (44.0 percent), Karnataka (38.5 percent), Punjab (33.8 percent), New Delhi (31.6 percent), Tripura (31.0 percent) and Gujarat (30.0 percent).

\footnotetext{
${ }^{1}$ Women's community group in rural areas.

${ }^{2}$ An early childhood development center in the rural areas and anganwadi worker provide integrated child development services and also engaged in promoting of various maternal and child health services.
} 
The above discussion supports the argument that there exists a wide variation in the utilization of maternal care services among mothers according to individual, program and community level characteristics. However, it is premature to draw any conclusions without having control on the socio-economic, program or community level characteristics. Hence a multivariate analysis is carried out controlling these variables. As mentioned in the methodology section, the statistical analysis of ordered logit regression with sample design correction is employed in order to control the effects of individual, program and community level variables. After estimating the model, the predicted values are generated and these results are provided instead of giving the coefficients. Dummy variables are created for most of the characteristics included in the analysis. The analysis also includes dummy variables representing each of the states in India. Various states in India are grouped into six regions as described in the NFHS report (IIPS and ORC Macro, 2000). The first region represents the southern states, states of western region are grouped into second region, northern states represent the third region, fourth region includes states from central India, the states from eastern area forms the fifth region and finally the northeastern states constitute the sixth region. The fourth region, i.e. the states from central India namely Madhya Pradesh and Uttar Pradesh, is treated as the reference category in the analysis.

Table 6 presents the adjusted effects of background, program and community characteristics on utilization of maternal care services.

Insert Table 6 about here

The table also indicates effects that are statistically significant at below 5 percent. The differentials in the adjusted percentages between various categories of the variables 
considered are smaller than that of the unadjusted percentages. However, the direction of the effect remains the same, except for age of mother at pregnancy. With the exception of women's work status, all of the household-level and individual-level socio-economic and demographic variables are found to have significant effects on the utilization of maternal care services, even after controlling for the potential confounding factors at the community levels. Thus it is evident that the use of maternal cares services is not determined merely by design and delivery strategies but also by the characteristics of potential users. Although, several of the socio-economic and demographic variables have statistically significant effect, large variations are found only according to birth order, education of mother, household standard of living and mother's exposure to mass media. Almost all the community level and program variables considered are found to be statistically significant in explaining the utilization of maternal care services in rural India. Availability of a health care provider in the village is the only community level variable, which was not significant on utilization of maternal care services.

\section{Conclusion}

This paper examined the utilization of maternal care services among women in rural India using the framework developed by Andersen and Newman (1973). Many limitations are found in the previous studies on utilization of maternal care services, such as non-inclusion of program factors, combining public and private health facilities and failing to capture the variations and complexity of the level of maternal care utilization. We have attempted to address these limitations through the inclusion of program variables, considering the access to public and private facilities separately and 
constructing a composite index based on the utilization of various components of maternal care services.

Utilization of maternal care services was measured using a composite index based on responses to three questions related to antenatal care services - number of antenatal visits, whether the mother received enough iron and folic acid tablets/syrup for more than three months and whether the mother received two or more tetanus toxoid shots during her pregnancy - and responses to two delivery care services - whether the mother received assistance from a health care professional at the time of delivery and the place of delivery. Further, this index was grouped into five categories namely, "Poor", "Fair", "Average", "Good" and "Excellent." Ordered logit regression with sample design correction was used to examine the determinants of utilization of maternal care services.

Significant variations in the use of maternal care utilization were observed in rural areas of India. Wide disparities in the use of maternal care were also found among all states. The percentage of rural women who used "excellent" maternal care varies from 5.7 percent in Uttar Pradesh to 92.0 percent in Kerala. The preliminary analysis of the unadjusted percentages of mothers using maternal care services shows a strong and consistent relationship between maternal care services and socioeconomic, demographic and community level variables. Similar to previous study findings, the present study also found significant influence of education, standard of living, and media exposure on the use of maternal care services. Among the community level variables, unadjusted values show sharp differentials in the use of maternal care. These include, the presence of a health facility within the village, the availability of mahila mandal or anganwadi center, and the organized IEC activities in the village. The differentials with respect to 
community factors further established the fact that as women become exposed to these varieties of health care service initiatives carried out through IEC programs or locally run mahila mandal or anganwadi center were more likely to adapt these messages into their behaviors.

The adjusted effects of the majority of the socioeconomic, demographic, community and program variables on the utilization of maternal care services were in the expected direction and statistically significant as well. But the variations between various categories are considerably smaller than the unadjusted effects. Among the various socioeconomic and demographic variables considered, only birth order, education of woman, household standard of living index and women's exposure to mass media have larger variations in the utilization of maternal care services, even after controlling for other predictor variables. Similarly, among various community level and program variables considered, a health worker visit during pregnancy and the distance to a government health facility also have strong and statistically significant influence on the utilization of maternal care services. Unlike previous studies using the National Family Health Survey -1 (NFHS-1) data, the present study showed that access to government and private health facilities have statistically significant effect on the utilization of maternal care services, even after controlling for the other predictor variables. The results also indicate the potential importance of program factors, especially the visit of a health worker during pregnancy, in explaining the better utilization of maternal care services in rural India. Similarly, the easy access to a government health facility also improves the utilization of maternal care services. Most importantly, adjusted values show that the mere presence of health care provider (such as a health facility) was not an indication of 
improving maternal care utilization. This further strengthened the importance of IEC activities and other similar programs, which incorporate health education and creating awareness about the use and benefits of maternal care.

The theoretical approach to study utilization of maternal care in India also enhanced our understanding in this area. The analysis suggested that the utilization of maternal care services was not determined only by the system and delivery strategies but also by the characteristics of mothers after controlling for program factors. The analysis also showed that the visit of a health worker during the pregnancy had some impact on the utilization of maternal care services. The present study also emphasized the importance of and need for subgroup population analysis to delineate the inequity in maternal care utilization in developing countries. Further studies are needed in this direction to help health care planners and policy makers in developing better-informed decisions in closing the gaps in inequity of maternal care utilization within society. 


\section{References}

Abbas, A., and G. Walker. 1986. Determinants of the utilization of maternal and child health services in Jordan. International Journal of Epidemiology 15(3): 404-407.

Abou-Zahr, Carla L., and Wardlaw, Tessa M. 2003.Antenatal Care in Developing Countries: Promises, Achievements and Missed Opportunities: An Analysis of Trends, Levels and Differentials, 1999-2001.World Health Organization: Switzerland.

Aday, L., and Andersen, R. 1974. A framework fro the study of access to medical care. Health Services Research 9(3): 208-220.

Andersen, Ronald M. 1968. Behavioral Model of Families' Use of Health Services. Research Series No. 25. Chicago, IL: Center for Health Administration Studies, University of Chicago.

Andersen, Ronald M. 1995. Revisiting the behavioral model and access to medical care: does it matter? Journal of Health and Social Behavior 36(March): 1-10.

Andersen, R and J. F. Newman (1973) Societal and individual determinants of medical care utilization in the United States. Milbank Memorial Fund Quarterly 51(1): 95-124.

Becker, Stan., Peter, David H., Gray, Ronald H., Bultiano, Connie., and Black, Robert E. 1993. The determinants of use of maternal and child health services in Metro Cebu, the Philippines. Health Transition Review 3(1): 77-91.

Ben Youssef, A., and A. Wessen. 1974. The utilization of health services in developing countries: Tunisia. Social Science and Medicine 8: 287-304.

Bhatia, J.C. 1993. Levels and causes of maternal mortality in southern India. Studies in Family Planning 24(5): 310-318.

Bhatia, Jagdish C., and John Cleland. 1995. Determinants of maternal care in a region of South India. Health Transition Review 5(2): 127-142.

Celik, Yusuf., and Hotchkiss, David R. 2000. The socio-economic determinants of maternal health care utilization in Turkey. Social Science and Medicine. 50(12): 17971806.

Chakraborty, Nitai., Islam, M. Athaharul., Chowdhury, Rafiqul Islam., Bari, Wasimul., and Akhter, Halida Hanum. 2003. Determinants of the use of maternal health services in rural Bangladesh. Health Promotion International 18(4): 327-337.

Das, N. P., V. K. Mishra, and P. K. Saha (2001) Does community access affect the use of health and family welfare services in Rural India?, National Family Health Survey

Subject Reports, Number 18. 
Duggal, R (1994) Health care utilization in India, Health for the Millions 2(1): 10-12.

Elo, Irma T. 1992. Utilization of maternal health care services in Peru: the role of women's education. Health Transition Review 2(1): 49-69.

International Institute for Population Sciences (IIPS) and ORC Macro (2000) National Family Health Survey (NFHS -2), 1998-99: India, Mumbai:IIPS.

Kanitkar, T., and Sinha, R.K. 1989. Antenatal care service in five states of India. In Population Transition in India, Vol. 2 by S.N. Singh (ed.). Delhi: B.R. Publishing.

Kwast, B., R. Rochat, and W. Kidane-Mariam. 1986. Maternal mortality in Addis Ababa, Ethiopia. Studies in Family Planning 17(6): 288-301.

Lane, Sandra D. 1994. From population control to reproductive health: an emerging policy agenda. Social Science and Medicine 39(9): 1304-1314.

Magadi, Monica Akinyi., Madise, Nyovani Janet., and Rodrigues, Roberto Nascimento. 2000. Frequency and timing of antenatal care in Kenya: explaining the variations between women of different communities. Social Science and Medicine 51(4): 551-561.

Matsumura, Masaki., and Gubhaju, Bina. 2001. Women's status, household structure and the utilization of maternal health services in Nepal. Asia-Pacific Population Journal 16(1): 23-44.

Moore, Wilbert E. 1969. Social structure and behavior. In Gardner Lindzey and Elliot Aronson (eds.), The Handbook of Social Psychology, Vol. 4. Reading, MA: AddisonWesley.

Navaneetham, K., and A. Dharmalingam. 2002. Utilization of maternal health care services in Southern India. Social Science and Medicine 55(10): 1849-1869.

Obermeyer, Carla Makhlouf., and Potter, Joseph E. 1991. Maternal health care utilization in Jordan: a study of patterns and determinants. Studies in Family Planning 22(3): 177187.

Phillips, Kathryn., Morrison, Kathleen R., Andersen, Ronald., and Aday, Lu Ann. 1998. Understanding the context of health care utilization: assessing environmental and provider-related variables in the behavioral model of utilization. Health Services Research 33(3): 571-596.

Raghupathy, Shobana. 1996. Education and the use of maternal health care in Thailand. Social Science and Medicine 43(4): 459-471.

Ramachandran, L. 1989. The effect of antenatal and natal services on pregnancy outcome and health of the mother and the child. Journal of Family Welfare 35(5): 34-46. 
World Health Organization. 1989. Preventing Maternal Deaths. Geneva: World Health Organization. 
Table 1. Individual and program variables used in the study.

\begin{tabular}{ll}
\hline Individual Variables & Program variables \\
\hline Age at pregnancy & Health worker visited during the pregnancy \\
Birth order & Distance to nearest transport facility \\
Woman's work status & Any IEC activity organized in the village \\
Education of woman & Availability of health professional in the village \\
Education of husband & Distance to nearest government health facility \\
Religion of the household head & Distance to nearest private health facility \\
Caste of the household head & Availability of mahila mandal in the village \\
Type of family & Availability of anganwadi center in the village \\
Standard of living index & \\
Woman's mass media exposure & \\
\hline
\end{tabular}




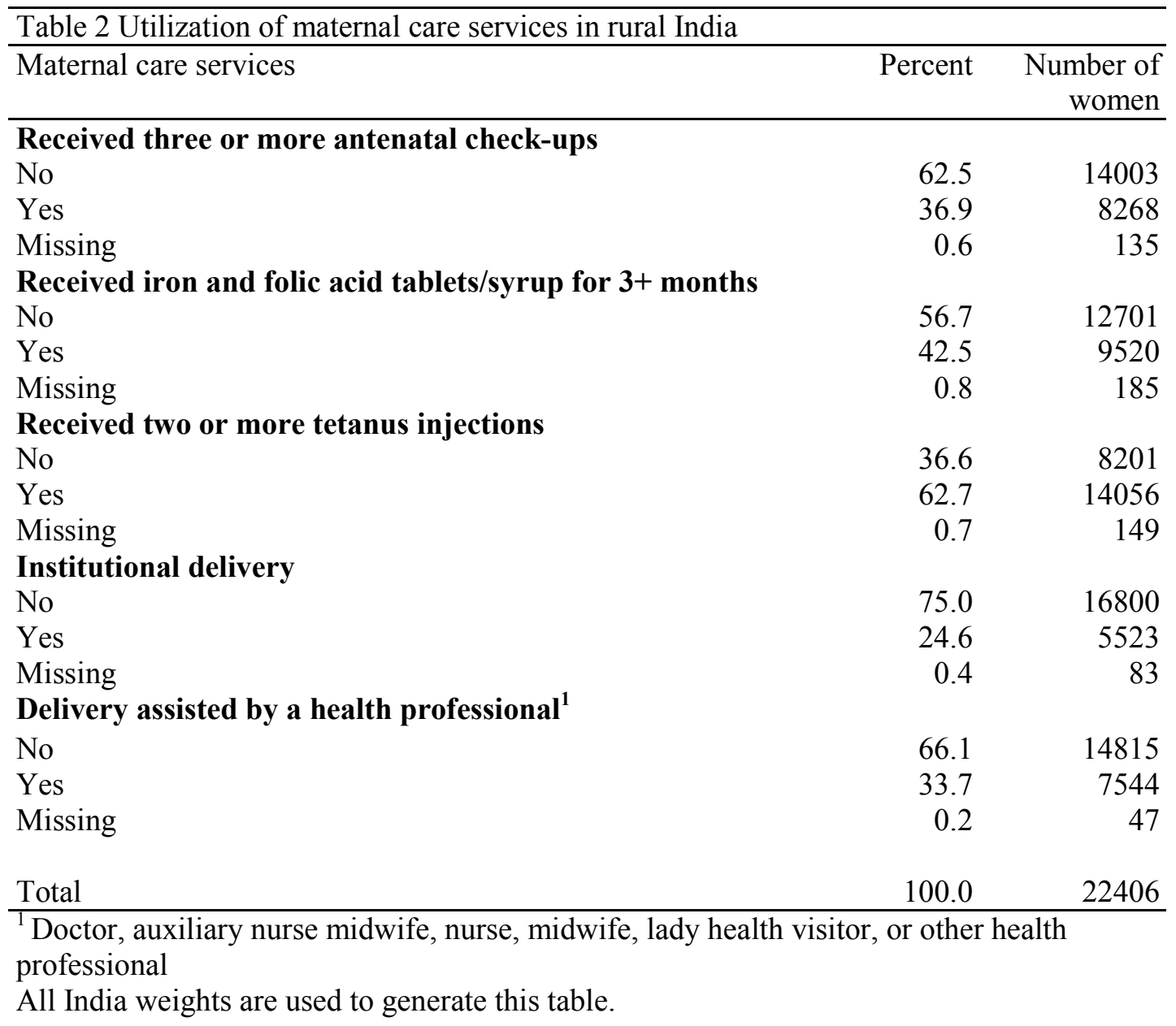




\begin{tabular}{|c|c|c|c|c|c|}
\hline \multirow[b]{2}{*}{ Individual characteristics } & \multicolumn{5}{|c|}{ Utilization of maternal care services } \\
\hline & Poor & Fair & Average & Good & Excellent \\
\hline \multicolumn{6}{|l|}{ Age at pregnancy } \\
\hline$<19$ years & 20.0 & 15.7 & 20.6 & 20.5 & 23.3 \\
\hline $20-24$ years & 18.8 & 17.5 & 18.9 & 20.9 & 23.8 \\
\hline $25-29$ years & 26.4 & 18.6 & 18.8 & 16.8 & 19.5 \\
\hline $30+$ years & 36.1 & 23.1 & 15.7 & 13.7 & 11.4 \\
\hline \multicolumn{6}{|l|}{ Birth order } \\
\hline 1 & 14.4 & 12.2 & 16.1 & 20.0 & 37.3 \\
\hline 2 & 17.1 & 15.6 & 20.2 & 21.8 & 25.3 \\
\hline 3 & 20.8 & 20.0 & 21.1 & 22.0 & 16.1 \\
\hline 4 & 28.0 & 21.7 & 21.4 & 17.7 & 11.3 \\
\hline $5+$ & 40.7 & 24.3 & 17.8 & 12.0 & 5.3 \\
\hline \multicolumn{6}{|l|}{ Woman's work status } \\
\hline Not working & 21.8 & 18.5 & 17.9 & 18.0 & 23.8 \\
\hline Working & 24.8 & 16.8 & 21.0 & 20.8 & 16.6 \\
\hline \multicolumn{6}{|l|}{ Education of woman } \\
\hline Illiterate & 31.4 & 22.1 & 19.8 & 16.6 & 10.2 \\
\hline Literate, $<$ middle complete & 9.8 & 12.4 & 21.9 & 25.2 & 30.8 \\
\hline Middle school complete & 4.8 & 9.9 & 16.7 & 24.9 & 43.8 \\
\hline High school complete and above & 2.5 & 5.5 & 10.0 & 19.4 & 62.6 \\
\hline \multicolumn{6}{|l|}{ Education of husband } \\
\hline Illiterate & 33.8 & 20.3 & 19.4 & 16.1 & 10.5 \\
\hline Literate, $<$ middle complete & 20.8 & 17.7 & 21.0 & 20.3 & 20.2 \\
\hline Middle school complete & 17.8 & 17.8 & 19.3 & 20.9 & 24.3 \\
\hline High school complete and above & 12.4 & 14.9 & 16.4 & 20.9 & 35.5 \\
\hline \multicolumn{6}{|l|}{ Religion of the household head } \\
\hline Hindu & 22.9 & 18.0 & 18.7 & 19.6 & 20.7 \\
\hline Muslim & 26.3 & 20.0 & 21.3 & 14.1 & 18.3 \\
\hline Other & 12.2 & 9.8 & 16.8 & 22.9 & 38.3 \\
\hline \multicolumn{6}{|l|}{ Caste of the household head } \\
\hline Scheduled caste & 24.3 & 19.6 & 19.2 & 20.1 & 16.9 \\
\hline Scheduled tribe & 35.1 & 17.9 & 21.6 & 17.3 & 8.1 \\
\hline Other backward caste & 21.8 & 19.3 & 16.1 & 18.3 & 24.6 \\
\hline None of them & 19.1 & 15.6 & 20.9 & 19.6 & 24.9 \\
\hline \multicolumn{6}{|l|}{ Type of family } \\
\hline Nuclear & 26.3 & 18.5 & 19.6 & 18.0 & 17.6 \\
\hline Joint family & 20.6 & 17.5 & 18.6 & 19.7 & 23.7 \\
\hline \multicolumn{6}{|l|}{ Standard of living index } \\
\hline Low & 30.2 & 20.3 & 20.0 & 16.8 & 12.8 \\
\hline Medium & 20.1 & 17.7 & 18.9 & 20.4 & 23.0 \\
\hline High & 5.2 & 9.4 & 15.3 & 22.2 & 47.9 \\
\hline \multicolumn{6}{|l|}{ Woman's mass media exposure } \\
\hline None & 33.7 & 22.7 & 19.9 & 14.9 & 8.8 \\
\hline One or two media & 12.7 & 15.0 & 20.0 & 24.8 & 27.5 \\
\hline Three or four media & 2.5 & 4.9 & 12.5 & 21.7 & 58.4 \\
\hline Total & 22.9 & 17.9 & 19.0 & 19.0 & 21.2 \\
\hline
\end{tabular}

All India weights are used to generate this table. 


\begin{tabular}{|c|c|c|c|c|c|}
\hline \multirow[t]{2}{*}{ Community level characteristics } & \multicolumn{5}{|c|}{ Utilization of maternal care services } \\
\hline & Poor & Fair & Average & Good & Excellent \\
\hline \multicolumn{6}{|c|}{ Health worker visited during the pregnancy } \\
\hline No & 28.5 & 19.6 & 17.4 & 16.0 & 18.4 \\
\hline Yes & 0.0 & 11.1 & 25.3 & 31.0 & 32.6 \\
\hline \multicolumn{6}{|l|}{ Distance to nearest transport facility } \\
\hline Within the village & 16.3 & 13.2 & 17.7 & 22.0 & 30.8 \\
\hline $1-4 \mathrm{kms}$ & 23.7 & 21.8 & 20.2 & 17.6 & 16.6 \\
\hline $5+\mathrm{kms}$ & 27.7 & 18.1 & 18.9 & 17.8 & 17.5 \\
\hline \multicolumn{6}{|l|}{ Any IEC activity organized in the village } \\
\hline No & 27.4 & 21.2 & 20.5 & 16.6 & 14.3 \\
\hline Yes & 15.6 & 12.6 & 16.6 & 22.8 & 32.4 \\
\hline \multicolumn{6}{|c|}{ Availability of health professional in the village } \\
\hline No & 27.4 & 19.7 & 19.3 & 17.4 & 16.2 \\
\hline Within the village & 19.3 & 17.7 & 17.4 & 19.3 & 26.4 \\
\hline Visiting health professional/health unit & 20.0 & 13.6 & 22.2 & 22.6 & 21.6 \\
\hline \multicolumn{6}{|c|}{ Distance to nearest government health facility } \\
\hline Within the village & 16.4 & 15.2 & 18.0 & 21.3 & 29.1 \\
\hline $1-4 \mathrm{kms}$ & 25.4 & 19.9 & 20.0 & 18.0 & 16.8 \\
\hline $5-9 \mathrm{kms}$ & 29.3 & 20.2 & 21.2 & 17.0 & 12.3 \\
\hline $10+$ & 41.4 & 21.8 & 15.4 & 12.4 & 9.0 \\
\hline \multicolumn{6}{|l|}{ Distance to nearest private health facility } \\
\hline Within the village & 16.6 & 14.0 & 17.2 & 21.2 & 30.9 \\
\hline $1-4 \mathrm{kms}$ & 23.1 & 20.8 & 19.3 & 17.2 & 19.7 \\
\hline $5-9 \mathrm{kms}$ & 22.4 & 18.4 & 20.6 & 19.7 & 18.9 \\
\hline $10+$ & 29.2 & 18.9 & 19.5 & 18.0 & 14.3 \\
\hline \multicolumn{6}{|c|}{ Availability of mahila mandal in the village } \\
\hline No & 27.7 & 21.2 & 19.4 & 16.5 & 15.1 \\
\hline Yes & 11.8 & 10.4 & 18.0 & 24.7 & 35.1 \\
\hline \multicolumn{6}{|c|}{ Availability of anganwadi center in the village } \\
\hline No & 30.5 & 21.4 & 18.4 & 15.6 & 14.1 \\
\hline Yes & 18.1 & 15.8 & 19.3 & 21.1 & 25.6 \\
\hline Total & 22.9 & 17.9 & 19.0 & 19.0 & 21.2 \\
\hline
\end{tabular}

All India weights are used to generate this table. 


\begin{tabular}{|c|c|c|c|c|c|}
\hline \multirow[b]{2}{*}{ State } & \multicolumn{5}{|c|}{ Utilization of maternal care services } \\
\hline & Poor & Fair & Average & Good & Excellent \\
\hline Andhra Pradesh & 6.1 & 6.4 & 13.2 & 30.3 & 44.0 \\
\hline Assam & 36.8 & 11.2 & 23.3 & 16.7 & 12.0 \\
\hline Bihar & 32.7 & 34.2 & 15.0 & 10.1 & 8.1 \\
\hline Goa & 0.0 & 0.6 & 2.7 & 9.3 & 87.4 \\
\hline Gujarat & 10.9 & 8.1 & 22.9 & 28.2 & 30.0 \\
\hline Haryana & 15.2 & 17.5 & 26.5 & 28.2 & 12.6 \\
\hline Himachal Pradesh & 10.8 & 8.8 & 24.2 & 32.4 & 23.8 \\
\hline Jammu \& Kashmir & 9.9 & 12.0 & 21.7 & 30.3 & 26.1 \\
\hline Karnataka & 13.3 & 5.4 & 14.7 & 28.2 & 38.5 \\
\hline Kerala & 0.2 & 0.7 & 0.4 & 6.7 & 92.0 \\
\hline Madhya Pradesh & 29.7 & 22.4 & 23.1 & 17.3 & 7.5 \\
\hline Maharashtra & 9.4 & 8.8 & 24.7 & 28.6 & 28.4 \\
\hline Manipur & 14.3 & 19.8 & 20.7 & 24.5 & 20.9 \\
\hline Meghalaya & 49.1 & 15.9 & 16.1 & 12.8 & 6.1 \\
\hline Mizoram & 12.4 & 11.4 & 20.8 & 37.7 & 17.7 \\
\hline Nagaland & 33.5 & 21.8 & 16.8 & 21.5 & 6.4 \\
\hline Orissa & 13.4 & 10.1 & 28.0 & 31.8 & 16.7 \\
\hline Punjab & 5.2 & 9.2 & 21.3 & 30.5 & 33.8 \\
\hline Rajasthan & 35.5 & 17.9 & 20.8 & 16.9 & 9.0 \\
\hline Sikkim & 26.9 & 15.1 & 18.3 & 18.5 & 21.2 \\
\hline Tamil Nadu & 0.8 & 1.0 & 6.6 & 22.3 & 69.3 \\
\hline West Bengal & 5.4 & 11.9 & 34.0 & 24.8 & 23.9 \\
\hline Uttar Pradesh & 40.7 & 28.0 & 15.9 & 9.7 & 5.7 \\
\hline New Delhi & 6.4 & 19.1 & 12.7 & 30.2 & 31.6 \\
\hline Arunachal Pradesh & 36.9 & 11.0 & 14.4 & 18.7 & 18.9 \\
\hline Tripura & 24.7 & 9.5 & 17.7 & 17.1 & 31.0 \\
\hline
\end{tabular}

Individual state weights are used to generate this table. 


\begin{tabular}{|c|c|c|c|c|c|c|}
\hline \multirow[b]{2}{*}{ Individual characteristics } & \multicolumn{5}{|c|}{ Utilization of maternal care services } & \multirow{2}{*}{$\begin{array}{l}\text { Whether } \\
\text { Significan }\end{array}$} \\
\hline & Poor & Fair & Average & Good & Excellent & \\
\hline \multicolumn{7}{|l|}{ Age at pregnancy } \\
\hline$<19$ years & 17.0 & 22.9 & 28.7 & 21.7 & 9.7 & YES \\
\hline $20-24$ years & 13.5 & 20.1 & 28.9 & 25.2 & 12.3 & YES \\
\hline $25-29$ years & 11.0 & 17.6 & 28.3 & 28.1 & 15.0 & NO \\
\hline $30+$ years $\AA$ & 11.0 & 17.6 & 28.3 & 28.0 & 15.0 & \\
\hline \multicolumn{7}{|l|}{ Birth order } \\
\hline 1 & 7.3 & 13.0 & 25.3 & 32.6 & 21.8 & YES \\
\hline 2 & 12.8 & 19.4 & 28.8 & 26.1 & 13.1 & YES \\
\hline 3 & 15.2 & 21.5 & 28.9 & 23.5 & 10.9 & YES \\
\hline 4 & 17.6 & 23.3 & 28.6 & 21.2 & 9.3 & YES \\
\hline $5+\AA$ & 23.9 & 26.5 & 26.6 & 16.5 & 6.5 & \\
\hline \multicolumn{7}{|l|}{ Woman's work status } \\
\hline Not working $®$ & 13.3 & 19.9 & 28.8 & 25.4 & 12.5 & \\
\hline Working & 14.0 & 20.5 & 28.9 & 24.7 & 11.9 & $\mathrm{NO}$ \\
\hline \multicolumn{7}{|l|}{ Education of woman } \\
\hline Illiterate ${ }^{\circledR}$ & 17.4 & 23.1 & 28.6 & 21.4 & 9.4 & \\
\hline Literate, $<$ middle complete & 10.2 & 16.7 & 27.9 & 29.0 & 16.1 & YES \\
\hline Middle school complete & 7.6 & 13.5 & 25.7 & 32.2 & 21.0 & YES \\
\hline High school complete and above & 5.7 & 10.7 & 22.8 & 34.2 & 26.6 & YES \\
\hline \multicolumn{7}{|l|}{ Education of husband } \\
\hline Illiterate ${ }^{\circledR}$ & 16.4 & 22.5 & 28.8 & 22.3 & 10.1 & \\
\hline Literate,$<$ middle complete & 12.8 & 19.4 & 28.8 & 26.0 & 13.0 & YES \\
\hline Middle school complete & 11.1 & 17.6 & 28.3 & 28.0 & 15.0 & YES \\
\hline High school complete and above & 12.2 & 18.8 & 28.7 & 26.7 & 13.6 & YES \\
\hline \multicolumn{7}{|l|}{ Religion of the household head } \\
\hline Hindu & 13.6 & 20.2 & 28.9 & 25.1 & 12.2 & NO \\
\hline Muslim $\AA$ & 14.5 & 20.9 & 28.9 & 24.2 & 11.5 & \\
\hline Other & 10.1 & 16.6 & 27.8 & 29.2 & 16.3 & YES \\
\hline \multicolumn{7}{|l|}{ Caste of the household head } \\
\hline Scheduled caste & 13.0 & 19.6 & 28.8 & 25.8 & 12.8 & YES \\
\hline Scheduled tribe ${ }^{\circledR}$ & 17.9 & 23.5 & 28.5 & 20.9 & 9.1 & \\
\hline Other backward caste & 13.8 & 20.4 & 28.9 & 24.9 & 12.0 & YES \\
\hline None of them & 12.4 & 19.0 & 28.7 & 26.4 & 13.4 & YES \\
\hline \multicolumn{7}{|l|}{ Type of family } \\
\hline Nuclear & 12.5 & 19.1 & 28.7 & 26.3 & 13.3 & YES \\
\hline Joint family® & 14.3 & 20.8 & 28.9 & 24.4 & 11.6 & \\
\hline \multicolumn{7}{|l|}{ Standard of living index } \\
\hline Low $\AA$ & 16.1 & 22.2 & 28.8 & 22.6 & 10.3 & \\
\hline Medium & 12.9 & 19.5 & 28.8 & 25.9 & 12.9 & YES \\
\hline High & 8.1 & 14.1 & 26.2 & 31.6 & 19.9 & YES \\
\hline \multicolumn{7}{|l|}{ Woman's mass media exposure } \\
\hline None ${ }^{\circledR}$ & 16.7 & 22.6 & 28.8 & 22.1 & 9.9 & \\
\hline One or two media & 11.2 & 17.8 & 28.3 & 27.8 & 14.8 & YES \\
\hline Three or four media & 8.7 & 14.9 & 26.8 & 30.9 & 18.6 & YES \\
\hline
\end{tabular}




\begin{tabular}{|c|c|c|c|c|c|c|}
\hline \multicolumn{7}{|l|}{ Table 6 contd. } \\
\hline \multirow[b]{2}{*}{ Community level characteristics } & \multicolumn{5}{|c|}{ Utilization of maternal care services } & \multirow{2}{*}{$\begin{array}{r}\text { Whether } \\
\text { Significant }\end{array}$} \\
\hline & Poor & Fair & Average & Good & Excellent & \\
\hline \multicolumn{7}{|c|}{ Health worker visited during the pregnancy } \\
\hline $\mathrm{No} \AA$ & 15.9 & 22.1 & 28.8 & 22.8 & 10.4 & \\
\hline Yes & 6.8 & 12.3 & 24.6 & 33.1 & 23.1 & YES \\
\hline \multicolumn{7}{|c|}{ Distance to nearest transport facility } \\
\hline Within the village & 14.3 & 20.8 & 28.9 & 24.3 & 11.6 & YES \\
\hline $1-4 \mathrm{kms}$ & 12.6 & 19.2 & 28.7 & 26.3 & 13.3 & $\mathrm{NO}$ \\
\hline $5+\mathrm{kms}^{\circledR}$ & 13.7 & 20.2 & 28.9 & 25.1 & 12.2 & \\
\hline \multicolumn{7}{|c|}{ Any IEC activity organized in the village } \\
\hline $\mathrm{No} \AA$ & 14.5 & 20.9 & 28.9 & 24.2 & 11.5 & \\
\hline Yes & 12.2 & 18.8 & 28.6 & 26.7 & 13.6 & YES \\
\hline \multicolumn{7}{|c|}{ Availability of health professional in the village } \\
\hline $\mathrm{No} \circledast$ & $13.5^{\circ}$ & 20.1 & 28.9 & 25.2 & 12.3 & \\
\hline Within the village & 13.9 & 20.4 & 28.9 & 24.8 & 12.0 & $\mathrm{NO}$ \\
\hline $\begin{array}{l}\text { Visiting health professional/health } \\
\text { unit }\end{array}$ & 12.9 & 19.5 & 28.8 & 25.9 & 12.9 & $\mathrm{NO}$ \\
\hline \multicolumn{7}{|c|}{ Distance to nearest government health facility } \\
\hline Within the village & $12.1^{\circ}$ & 18.7 & 28.6 & 26.8 & 13.7 & YES \\
\hline $1-4 \mathrm{kms}$ & 14.2 & 20.7 & 28.9 & 24.5 & 11.7 & YES \\
\hline $5-9 \mathrm{kms}$ & 15.4 & 21.7 & 28.9 & 23.2 & 10.7 & NO \\
\hline $10+\AA$ & 17.3 & 23.1 & 28.6 & 21.5 & 9.5 & \\
\hline \multicolumn{7}{|c|}{ Distance to nearest private health facility } \\
\hline Within the village & 12.8 & 19.4 & 28.8 & 26.0 & 13.0 & YES \\
\hline $1-4 \mathrm{kms}$ & 12.0 & 18.7 & 28.6 & 26.9 & 13.8 & YES \\
\hline $5-9 \mathrm{kms}$ & 13.6 & 20.2 & 28.9 & 25.1 & 12.2 & YES \\
\hline $10+\AA$ & 15.9 & 22.1 & 28.8 & 22.8 & 10.4 & \\
\hline \multicolumn{7}{|c|}{ Availability of mahila mandal in the village } \\
\hline $\mathrm{No} \circledast$ & 14.3 & 20.8 & 28.9 & 24.4 & 11.6 & \\
\hline Yes & 11.9 & 18.5 & 28.6 & 27.0 & 14.0 & YES \\
\hline \multicolumn{7}{|c|}{ Availability of anganwadi center in the village } \\
\hline $\mathrm{No}{ }^{\circledR}$ & 15.0 & 21.4 & 28.9 & 23.7 & 11.1 & \\
\hline Yes & 12.7 & 19.3 & 28.8 & 26.1 & 13.1 & YES \\
\hline Total & 13.6 & 20.1 & 28.9 & 25.2 & 12.3 & \\
\hline
\end{tabular}


Appendix A.1.

Percentage of mothers who had their last birth during the three years preceding the survey according to selected background characteristics, Rural India, 1998-2000

\begin{tabular}{|c|c|c|}
\hline Background characteristics & Percent & Number of cases \\
\hline \multicolumn{3}{|l|}{ Age at pregnancy } \\
\hline$<19$ years & 29.4 & 6175 \\
\hline $20-24$ years & 37.1 & 7793 \\
\hline $25-29$ years & 21.2 & 4453 \\
\hline $30+$ years & 12.3 & 2595 \\
\hline \multicolumn{3}{|l|}{ Birth order } \\
\hline 1 & 25.7 & 5401 \\
\hline 2 & 24.7 & 5198 \\
\hline 3 & 18.8 & 3960 \\
\hline 4 & 11.6 & 2432 \\
\hline $5+$ & 19.2 & 4025 \\
\hline \multicolumn{3}{|l|}{ Woman's work status } \\
\hline Not working & 64.1 & 13472 \\
\hline Working & 35.9 & 7544 \\
\hline \multicolumn{3}{|l|}{ Education of woman } \\
\hline Illiterate & 65.6 & 13794 \\
\hline Literate, $<$ middle complete & 17.3 & 3629 \\
\hline Middle school complete & 7.8 & 1647 \\
\hline High school complete and above & 9.3 & 1946 \\
\hline \multicolumn{3}{|l|}{ Education of husband } \\
\hline Illiterate & 35.6 & 7484 \\
\hline Literate, $<$ middle complete & 24.8 & 5203 \\
\hline Middle school complete & 14.3 & 3007 \\
\hline High school complete and above & 25.3 & 5322 \\
\hline \multicolumn{3}{|l|}{ Religion of the household head } \\
\hline Hindu & 81.9 & 17213 \\
\hline Muslim & 13.6 & 2850 \\
\hline Other & 4.5 & 953 \\
\hline \multicolumn{3}{|l|}{ Caste of the household head } \\
\hline Scheduled caste & 21.3 & 4478 \\
\hline Scheduled tribe & 11.1 & 2329 \\
\hline Other backward caste & 33.6 & 7061 \\
\hline None of them & 34.0 & 7148 \\
\hline \multicolumn{3}{|l|}{ Type of family } \\
\hline Nuclear & 40.5 & 8515 \\
\hline Joint family & 59.5 & 12501 \\
\hline \multicolumn{3}{|l|}{ Standard of living index } \\
\hline Low & 43.26 & 9092 \\
\hline Medium & 46.15 & 9698 \\
\hline High & 10.59 & 2226 \\
\hline \multicolumn{3}{|l|}{ Woman's mass media exposure } \\
\hline None & 54.6 & 11482 \\
\hline One or two media & 32.7 & 6866 \\
\hline Three or four media & 12.7 & 2668 \\
\hline Total & 100.0 & 21016 \\
\hline
\end{tabular}

All India weights are used to generate this table. 
Appendix A. 2.

Percentage of mothers who had their last birth during the three years preceding the survey according to selected community level characteristics, Rural India, 1998-2000

\begin{tabular}{lrr}
\hline Community level characteristics & Percent & $\begin{array}{r}\text { Number of } \\
\text { cases }\end{array}$ \\
\hline Health worker visited during the pregnancy & & 16854 \\
No & 80.2 & 4162 \\
Yes & 19.8 & \\
Distance to nearest transport facility & 30.0 & 6318 \\
Within the village & 34.4 & 7223 \\
1-4 kms & 35.6 & 7475 \\
5+ kms & & \\
Any IEC activity organized in the village & 61.6 & 12944 \\
No & 38.4 & 8072 \\
Yes & & \\
Availability of health professional in the village & 43.3 & 9099 \\
No & 40.5 & 8509 \\
Within the village & 16.2 & 3408 \\
Visiting health professional/health unit & & \\
Distance to nearest government health facility & 45.2 & 9506 \\
Within the village & 34.2 & 7183 \\
1-4 kms & 14.5 & 3048 \\
5-9 kms & 6.1 & 1279 \\
10+ & & \\
Distance to nearest private health facility & 28.3 & 5945 \\
Within the village & 25.5 & 5368 \\
1-4 kms & 18.0 & 3772 \\
5-9 kms & 28.2 & 5931 \\
10+ & & \\
Availability of mahila mandal in the village & 69.6 & 14633 \\
No & 30.4 & 6383 \\
Availability of anganwadi center in the village & & \\
No & 38.3 & 8048 \\
Yes & 61.7 & 12968 \\
Total & & \\
\hline Al & 100.0 & 21016 \\
\hline
\end{tabular}

All India weights are used to generate this table. 